\title{
Collective Action and Carbon Sequestration in Nepal
}

\author{
Randall Bluffstone ${ }^{1}$, Eswaran Somanathan ${ }^{2}$, Prakash Jha ${ }^{3}$, Harisharan Luintel, \\ Rajesh Bista ${ }^{5}$, Michael Toman ${ }^{6}$, Naya Sharma Paudel ${ }^{7}$, Bhim Adhikari $^{8}$ \\ ${ }^{1}$ Portland State University-USA, ${ }^{2}$ Indian Statistical Institute-India, ${ }^{3}$ University of Venice Ca Foscari-Italy and ForestAction-Nepal, \\ ${ }^{4}$ Portland State University-USA and ForestAction-Nepal ${ }^{5,7}$ ForestAction-Nepal, ${ }^{6}$ World Bank-Washington DC, ${ }^{8}$ IDRC-Canada \\ Corresponding author: bluffsto@pdx.edu
}

\begin{abstract}
This paper uses forest plot measurements and information on forest collective action to estimate the effects of collective action on four measures of forest quality (e.g., carbon content, tree density, seedling density and canopy cover) in Nepal. Carbon sequestration is of special interest because it may be creditable under Reducing Emmission from Deforestation and Forest Degradation (REDD+). We find that community forest collective action sequesters carbon and appears to support several other forest quality measures. Even though registered community forests sequester more carbon than other forests, we find that non-registered community forests also show evidence of important collective action, with positive effects on forests.
\end{abstract}

Key words: Carbon, collective action, Nepal, REDD+, sequestration

\section{IMPORTANCE OF THE ISSUES}

Recent evidence suggests that the earth is hotter now than about $3 / 4$ of the last 11,000 years Marcott et al. (2013), and IPCC (2014) evaluated with medium confidence that the period 1983-2012 was hotter than the last 1400 years. Based on ice core evidence, IPCC (2014) also noted that the concentration of greenhouse gases (GHGs) in the atmosphere is now greater than at least the last 800,000 years. While GHG concentrations continue to rise, the climate will continue to adjust just to the existing concentrations through further warming for over 1000 years (Archer 2009).

Under the 1992 United Nations Framework Convention on Climate Change (UNFCCC), only the relatively wealthier 41 countries listed in Annex 1 out of a total of almost 200 countries have obligations to reduce GHG emissions. At least at present, non-Annex 1 countries (developing countries and countries with economies in transition) do not have formal treaty obligations, though many made pledges at the 2009 Conference of Parties to the Convention in Copenhagen to undertake "Nationally Appropriate Mitigation Actions (NAMAs)" and will presumably announce voluntary mitigations under the agreement in future. Developing countries can also obtain economic incentives to reduce emissions under the Framework Convention and subsequent agreements of the Parties.

One important area for cooperation in mitigation is in the area of forestry and land use change. Through the United Nations Collaborative Programme on Reducing Emissions from Deforestation and Forest Degradation (REDD+), UNFCCC Annex 1 countries provide financial support to nonAnnex 1 countries, such as Nepal, in exchange to verified reductions in actual or potential deforestation and forest degradation. These reductions could represent important climate change contributions, because deforestation and forest degradation account for 12 per cent to 20 per cent of the annual GHG emissions. In the 1990s, forests released about $5.8 \mathrm{Gt}$ carbon per year, largely from the developing world, which was more than all forms of transport combined (Saatchi et al. 2011; van der Werf et al. 2009).

While REDD+ is being rolled out, an important and outstanding question is how to incorporate the forest in developing countries that are being managed by the local communities. These community forests may contain 
significant carbon that may be protected under REDD+ and collective action may even now be sequestering carbon.

Understanding the role of community forests in climate change mitigation is important because 25 per cent of the developing country forests are under effective community management (World Bank 2009; Economist 2010) and the share in low-income countries is no doubt much higher. Forests are the key source of carbon sinks and potential greenhouse gas emissions, and community forests are about a quarter of the developing country forests, where virtually 100 per cent of net forest biomass loss is taking place. This makes it difficult to address climate change without bringing community forests into REDD+. At the same time, forests in most low-income developing countries provide products that are essential to the daily lives of people, including fuel wood, forest fruits and vegetables, building materials and animal fodder (Cooke et al. 2008). Therefore, significant opportunity costs of sequestration may exist.

The chain connecting collective action and carbon stocks runs through better management and higher forest quality. Better quality forests have more biomass because reduced fuelwood, timber and fodder collections reduce pressures on forests allowing them to regenerate. Better management is what drives these results and in community setting, these are potentially the result of collective action where community members work together to achieve shared goals.

The question that our research attempts to answer is whether forests governed under more formalized collective action have sequestered more carbon. We also examine whether they generally have better quality forests. Groups that are part of the Nepal Community Forestry Programme (CFP) are of special interest but we also analyze collective action that occurs completely outside the CFP compared with presumed open access in which there may be no collective actions or controls on extractions from forests.

Evaluating the effect of collective action on carbon stocks does not tell policymakers whether REDD+ is good for Nepal, and in particular for the many local residents who control and manage forests. It does, however, shed light on the types of collective action in Nepal that sequester carbon, thereby helping to mitigate climate change. This information is important for assessing how community forests may potentially contribute to REDD+.

We find that collective action measured in three different ways is important for carbon sequestration. UNFCCC Annex 1 funders and non-Annex 1 governments (and land users) thus should consider supporting forest community collective action through approaches that credit collective action under REDD+. However, an important question not touched upon in the research is how to undertake crediting for improved community action - in particular, how to establish the "additionality" that allows reductions to be credited and payments to be made under REDD+.

\section{STUDY CONTEXT, DATA AND METHODS}

Nepal launched the CFP in the late 1980s in the context of severe deforestation and forest degradation. The underpinnings of the program were specified in the 1989 Master Plan for the Forestry Sector. This plan recognized the role of local communities in forest management, redefined the role of state to facilitate local initiatives and appreciated that forests meet diverse needs at the local level. The CFP was enshrined in legislation with the Forest Act of 1993, which provided a clear legal basis and enabled the government to hand over national forests to the local community forest user groups (CFUGs). As of 2014, the CFP included over 18,000 CFUGs, involving over 2.2 million households and 1.7 
million hectares of forest. These community forests are believed to have improved forest quality compared to those with government management. They are also believed to have increased social services, incomes and employment and strong local institutions.

In this research, we randomly select 65 CFP forests and associated user groups (15 in Terai $^{1}$ and 50 in the hills) from the national representative sample of Hobley and Jha (2012). Researchers at ForestAction Nepal, based on their field knowledge, then chose 65 non-community forest sites (50 in Terai and 15 in the hills) in nearby, ecologically and socially similar areas. Non-CFP sites were selected so they resembled the CFP sites to the extent possible in all senses except they had not been handed over as community forests to the local communities. Selected non-CFP sites were also proximate to the CFP sites (e.g. in the same district), but in no cases were they adjacent to the sampled CFP sites.

The sample sites are presented in Figure 1 by location (hill versus Terai) and CFP status. More CFP forests were sampled in the hills and fewer in the Terai, because the population of CFP forests is present mainly in the hills. As suggested in Figure 1, our sample well covers Nepal and we do believe it is representative. A total of 620 plot samples, each of $250 \mathrm{~m}^{2}$ in area were taken in these 130 forests.Forest quality was then measured at the plot level in terms of the following metrics:

1. Total carbon in kilogram per hectare $^{2}$

2. Number of trees per hectare

3. Canopy cover in per cent

4. Seedlings per hectare

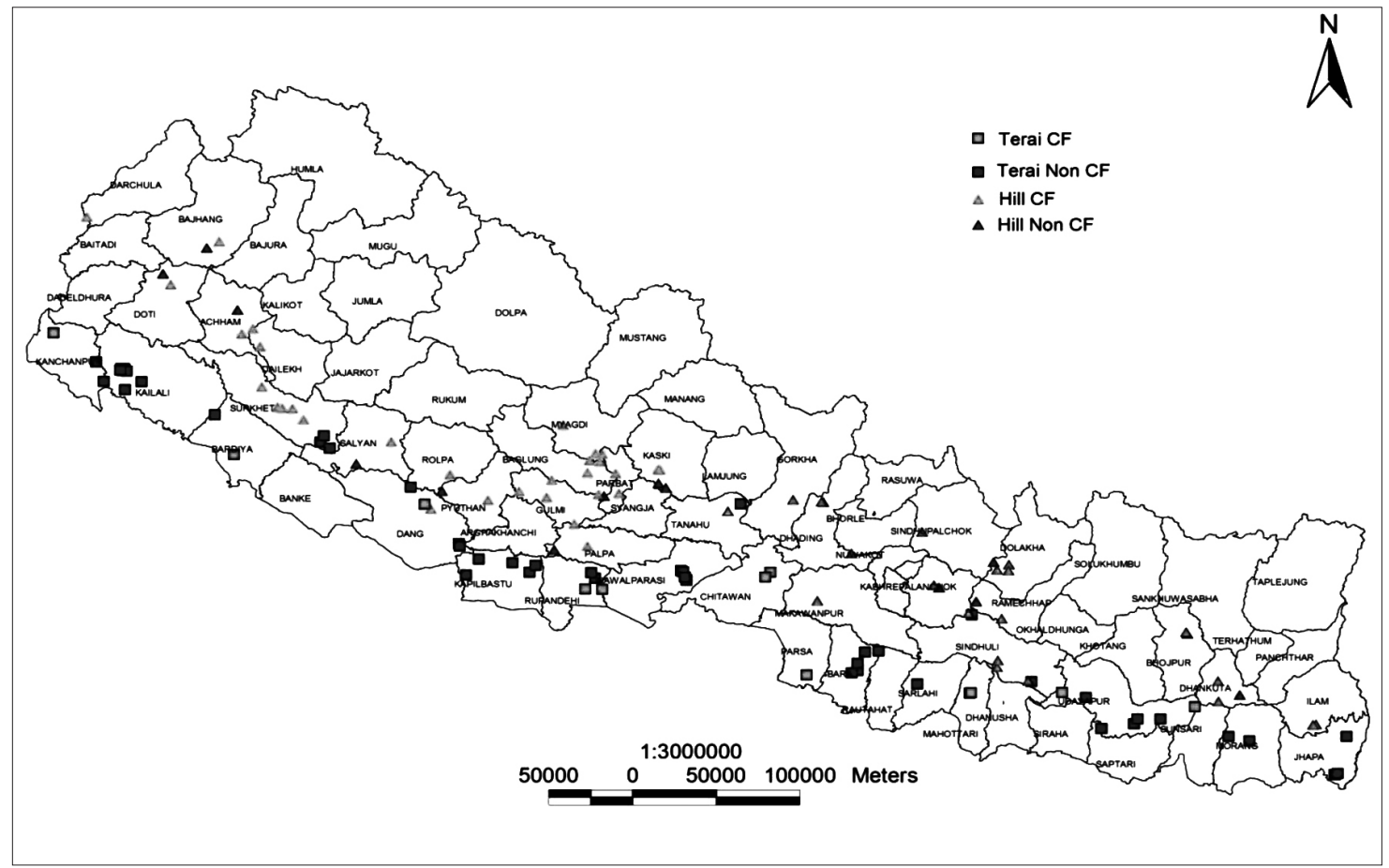

Figure 1: Sample Forests and User Groups

\footnotetext{
${ }^{1}$ Terai represents the southern plains of the country bordering with India.

${ }^{2}$ Total carbon is based on biomass estimated using allometric equations from Chave $e t$ al. (2005). Carbon is estimated using the IPCC (2006) default value of 0.5 tons of carbon per ton of biomass.
} 
These measures capture different aspects of forest quality. Carbon is of primary interest for REDD+ in this research paper, but it is possible that a few large trees on a plot have lots of carbon. However, there may be a little of other vegetation that hardly is a sign of a healthy forest. We therefore counted trees per hectare and analyzed those as a measure of forest quality. In Nepal, villagers often lop branches for fodder and fuel, leading to overe estimation of forest biomass. We adjusted the lopping by estimating the per cent canopy cover above each plot. Enumerators subjectively measured this canopy cover. Finally, regeneration is an important measure of future forest health. These were counted in $1 \mathrm{~m}^{2}$ plots located exactly at the center of each $250 \mathrm{~m}^{2}$ forest plot.

The determinants of the four measures of forest quality (including sequestered carbon) were investigated at both plot and forest levels. Our main interest in this paper is in the effect of collective action on carbon sequestration. Three measures of collective action were used, including the following:

- Narrowdefinition:Forests and communities are registered under the CFP

- Modest definition: Forests and communities are registered or proposed under the CFP.

- $\quad$ Broad definition: Forest and community are not registered under the CFP, but village leaders are able to report the year forest user groups were established. All CFP communities and most of the proposed CFPs can identify group formation years.

These collective action measures focus on forest governance rather than management, which is another way to measure collective action. Our governance measures range from narrow to broad where communities are registered and operating CFPs. The narrowest measures test the impact of the CFP legal structure vis-à-vis communities not officially in the program, though it should be recognized that spillover effects of CFP norms could affect non-CFP communities; the way CFP communities operate may therefore influence behaviors in non-CFP communities.

The broader measures recognize that communities in our sample that are not CFPs may show significant evidence of collective action. For example, even though they have no legal status, 37 of 65 non-CFP leaders are able to identify the year their forest user group was formed. The first group started in 1991 and the most recent non-CFP "group" was established in 2012. ${ }^{3}$ Our community survey also indicates that 74 per cent of nonCFP group leaders agreed or strongly agreed with the statement "the community forest has clear boundaries between legitimate users and nonusers and nonusers are effectively excluded." Furthermore, 68 per cent of the leaders reported that they have "... formal, informal or customary rules and regulations that govern the access, use (barvesting) and maintenance (management) of the forest" and 22 of 65 say these rules are merely in writing. We believe that most of these behaviors can only be in place if there is an identifiable group formation year and we therefore use identification of group formation year as indicative of more extensive collective action.

Environmental factors (e.g. plot slope, aspect, altitude and total forest area) and community (forest per household and households in user groups) believed to affect forest quality are also included in models to avoid bias. Most importantly, we adjusted for 1990 baseline forest quality using the forest-level average Normalized Difference Vegetation Index (NDVI). This Landsat-based measure estimates an index of vegetation from 1990, which is not entirely before all collective actions began, but is three years before the Forest Act that officially established the CFP. It therefore gives an important measure of forest quality before the CFP officially began.

${ }_{3}^{3}$ All CFP communities can, of course, identify such years, because it is legally recognized. Eighteen of 23 proposed CFPs can identify their group formation year. 


\section{FINDINGS}

Using our sampling methodology we find as shown in Table 1 that the average hectare of forest in Nepal has about 92 tons of carbon. This carbon is approximately 97 per cent from tree biomass and only 3 per cent from saplings.
The average hectare is also estimated to have 561 trees and 30,000 seedlings. The average plot is subjectively estimated to have 48 per cent canopy cover.

Table 1 Forest Quality Measures

\begin{tabular}{llll}
\hline Variable & Observations & Mean & Standard Deviation \\
\hline Total carbon in kg per hectare & 130 & $92,410.33$ & $76,074.89$ \\
Number of trees per hectare & 130 & 560.6894 & 402.1309 \\
Canopy cover in percent & 130 & 48.61507 & 19.73628 \\
Seedlings per hectare & 130 & $30,356.32$ & $26,124.46$ \\
\hline
\end{tabular}

As shown in Table 2, on average, Terai forests have about $1 / 3$ more carbon per hectare than hill forests even though sample forests average about 92 tons of carbon per hectare. We also see that within hills and Terai regions carbon sequestration is slightly more if forests are managed as CFP, but the difference is extremely small and we find it to be statistically insignificant. Examining simple averages, therefore, suggests that CFP forests may sequester no more carbon than other forests.
This conclusion largely holds up in statistical models that adjust for other factors (including 1990 NDVI, biophysical characteristics and selected community features) unless CFP plots are explicitly matched with similar plots outside the CFP system. After matching at the plot level, CFP forests are found to sequester on average 23 tons more carbon per hectare or about 25 per cent of the sample mean. ${ }^{4}$

Table 2 Average Carbon Per Hectare by Forest (tons)

\begin{tabular}{llll}
\hline & Hill & Terai & All CFP/non-CFP \\
\hline CFP & $76.1(71.1)$ & $118.3(103.0)$ & $89.7(84.3)$ \\
Non-CFP & $72.1(70.4)$ & $102.0(65.6)$ & $95.1(67.4)$ \\
All Hill/Terai & $75.1(70.3)$ & $106.8(78.1)$ & \\
\hline
\end{tabular}

Standard deviations in parentheses

The CFP sequesters more carbon than nonCFP forests, but it does not provide a unique path to gains. Indeed, the largest carbon gains per hectare accrue to plots and forests governed by the broadest collective action definition. In comparison to the 43 communities that cannot identify the year in which their forest user group was established (i.e. presumably open access), these communities sequester between 40 and 74 more tons of carbon per hectare than those governed under open access. These gains represent 43-79 per cent of mean carbon, which suggests that collective action has huge effects vis-à-vis open access.

If we remove all non-CFP communities from the subsample of those that can identify their group formation year, we find the smaller effects noted above (23 tons more carbon per hectare or about 25 per cent of the sample mean). This result strongly suggests that

\footnotetext{
${ }^{4}$ Results are similar at the forest level, but the estimate is not statistically different from zero
} 
non-CFP communities - that are engaged in collective action - are sequestering significant carbon. Conversely, open access forests are estimated to have only 21-57 per cent of the forests carbon governed under collective action.

Forests that are either CFP or proposed CFP forests are estimated to have 26- 50 more tons of carbon per hectare than forests that have no linkage to the CFP program. We also find that these have about 11,000 more seedlings per hectare and in the plot level models about 96 more trees (about 20 per cent more) per hectare.

\section{DISCUSSION AND CONCLUSION}

In this paper, we use detailed forest plot measurements and information on forest collective action to estimate the effect of collective action on four measures of forest quality. This paper focuses on the effects of collective action on carbon sequestration estimated using nearest neighbor propensity score matching. The effects of these collective action measures are compared with counterfactual communities that do not have those collective action characteristics. For example, CFP forests are compared with all communities outside the CFP, which may not necessarily be open access forests.

The findings in this paper strongly suggest that in community forestry settings, collective action promotes carbon sequestration for direct use forest ecosystem services, like availability of fuelwood and fodder. However, we find that these important collective action effects are also currently occurring outside the CFP. When we make the open access communities the comparator group, the estimated carbon storage effects of collective action are at their highest levels. This finding suggests that non-CFP communities who are engaged in collective action, sequester significant carbon. If all these groups were brought under the
CFP umbrella, these gains would, of course, be defined as CFP carbon.

This conclusion that non-CFP communities sequester carbon is not surprising, because many non-CFP communities report extensive collective action, including group formation dates, the existence of harvest rules and clear boundaries separating users and non users. If identification of group formation year is an indicator of this more complex collective action, it suggests that these unofficial and perhaps earliest steps toward collective action and away from open access offer the largest gains.

What are the carbon policy implications of these results? We believe the findings strongly suggest that REDD+ funders and the Government of Nepal, as part of its REDD+ Readiness Program, should actively support, fund and facilitate good forest governance at the community level. As it seems very unlikely that carbon sequestration can be credited outside the CFP program, a corollary is that the Government of Nepal should expedite the handover of non-CFP forests and bring them into the CFP. The evidence suggests that there are significant carbon sequestration benefits from such community collective action and we believe that communities should receive that credit. REDD+ may also be important for incentivizing formal collective action, as well as assuring that existing carbon sequestration is maintained.

\section{REFERENCES}

Archer, D. 2009. The Long Thaw: How Humans are Changing the Next 100,000 Years of Earth's Climate. Princeton: Princeton University Press.

Chave, J., Andalo, C., Brown, S., Cairns, M., Chambers, J. and Eamus, D. 2005. Tree Allometry and Improved Estimation of Carbon Stocks. Oecologia, 145: 87-99.

Cooke, P., Köhlin, G. and Hyde, W. F. 2008. Fuelwood, Forests and Community Management - Evidence from Household Studies. Environment and Development Economics, 13:103-135. 
Economist. 2010. Not a Small Problem: Will REDD Trample on the Rights of Traditional Forest Folk? The Economist, 23 September, 2010.

Hobley, M. and Jha, C. 2012. Persistence and Change: Review of 30 years of Community Forestry in Nepal. Kathmandu: HURDEC Nepal.

IPCC. 2006. Good Practice Guidelines for National Greenhouse Gas Inventories. Switzerland: Intergovernmental Panel on Climate Change.

IPCC. 2014. Climate Change 2014: Impacts, Adaptation and Vulnerability. Switzerland: Intergovernmental Panel on Climate Change.

Marcott, S., Shakun, J., Clark, P. and Mix, A. 2013. A Reconstruction of Regional and Global Temperature for the Past 11,300 Years. Science, 339: 1198-1201.
Saatchi, S.S., Harris N.L., Brown S., Lefsky, M., Mitchard, T.A.E., Salas, W., Zutta, B.R., Buermann, W., Lewis, S.L., Hagen, S., Petrova, S., White, L., Silman, M. and Morel, A. 2011. Benchmark Map of Forest Carbon Stocks in Tropical Regions Across Three Continents. PNAS, 108(24): 9899-9904.

van der Werf, G. R., Morton, D. C., DeFries, R. S., Olivier, J. G. J., Kasibhatla, P. S., Jackson, R.B., Collatz, G.J., Randerson, J.T. 2009. $\mathrm{CO}_{2}$ Emissions from Forest Loss. Nature Geoscience, 2: $737-738$.

World Bank. 2009. Forests Sourcebook: Practical Guide for Sustaining Forests in International Cooperation. Washington, D.C.: The World Bank. 